\title{
Comparing two models that reduce the number of nephrology fellowship positions in the United States
}

Tejas Desai

There has been a steady decline in the number of applications to nephrology training programs. One solution is to decrease the number of available fellowship positions. Proponents believe that training programs have grown too big but the method for reduction has not been established. This investigation analyzes two models that decrease the number of available training positions and compares them head-to-head to identify the least burdensome method by which this reduction should occur. In the survival of the fittest model (SotFM) fellowship positions are eliminated if they were unfilled in the National Residency Match Program's (NRMP) 2013 Specialty Match. In the equal proportions model (EPM) a formula is used to calculate a priority score using ESRD prevalence data from the 2013 USRDS Report and the geometric mean between a given jurisdiction's current apportionment $(n)$ and its next position $(n+1)$. The least burdensome model is that which results in the 1 ) least number of jurisdictions losing fellow positions and 2) lowest percent reduction for any single jurisdiction. There were 416 nephrology positions offered and 47 unfilled in 2013. In the SotFM, 23 jurisdictions would sacrifice these 47 positions. In the EPM, 369 positions were apportioned (=416-47) ; only 9 jurisdictions would experience a reduction. The largest single-jurisdiction reduction in fellow positions was $67 \%$ (SotFM) and 50\% (EPM). The EPM results in a less burdensome reduction of fellow positions nationwide. The EPM is a time-tested model that injects fairness into the painful process of reducing the total number of fellow positions across America. 
1 Comparing two models that reduce the number of Nephrology fellowship

2 positions in the United States

3 Tejas Desai, MD

4 Division of Nephrology and Hypertension, East Carolina University, Greenville,

5 NC 27834 USA

6 Corresponding Author: Tejas Desai

72355 West Arlington Blvd

8 Greenville, NC 27834

9 Tejas.p.desai@gmail.com

$10 @$ @ephondemand

11 Number of Figures 3

12 Number of Tables 2

13 Disclaimer: TD is the creator of Nephrology On-Demand Plus

14 (http://goo.gl/tfSAQT). The data reported here have been supplied by the

15 United States Renal Data System (USRDS). The interpretation and reporting

16 of these data are the responsibility of the author(s) and in no way should be

17 seen as an official policy or interpretation of the U.S. government.

18 Anonymous comments and queries are encouraged and can be viewed at:

19 https://storify.com/nephondemand/comments-for 
There has been much debate regarding the decrease in applications to

22 Nephrology training programs. For more than a decade, the number of

23 applications has steadily dropped while the number of explanations and

24 solutions for this decline has risen [Desai et al., 2012; Jhaveri et al., 2013].

25 These solutions are as varied and unique as the individuals who propose

26 them. One commonly proposed solution is to simply decrease the available

27 number of fellow positions [Desai, 2014]. Proponents argue that fellowship

28 programs have grown too big and have overestimated the interest that

29 resident physicians have in Nephrology careers [Berns et al., 2014]. From

302009 to 2013, the applicant-to-position ratio, a common metric used to

31 characterize the demand for positions, has steadily fallen from 1.6 to 1.01

32 (2010: 1.5; 2011: 1.3; 2012: 1.1) [National Residency Matching Program,

33 2013]. Many influential voices, including leaders of the American Society of

34 Nephrology (the largest professional society of Nephrologists) have voiced

35 this recommendation through formal reports [Berns et al., 2014; Salsburg et

36 al., 2014]. However, there is no consensus on how the excess positions

37 should be eliminated. In this investigation, we analyze two models that

38 decrease the number of available training positions and compare them head-

39 to-head to identify the least burdensome method by which this reduction

40 should occur.

41 Methods

42 Data Set

43 The two models rely on two separate data sets. The first model, known

44 as the Survival of the Fittest (SotFM), uses data from the 2013 National

45 Residency Match Program's (NRMP) Specialty Match Report for Nephrology

46 [National Residency Matching Program, 2013]. This report contains statewide

47 information about available fellowship positions, number of applicants, and

48 number of unmatched positions. The second model, known as Equal

49 Proportions (EPM), uses data from the same NRMP Specialty Match Report

50 along with 2011 statewide prevalence of end-state renal disease (ESRD)

51 patients from the 2013 United States Renal Data System (USRDS) Report [US

52 Renal Data Systems, 2013].

53 Survival of the Fittest Model (SotFM)

54

In this model, the number of fellowship positions that should be

55

56

57 eliminated is equal to the number of unmatched positions in the 2013 NRMP Specialty Match. Briefly, since 2009 the NRMP has used its proprietary and confidential matching algorithm to pair an applicant with his/her single most 
58 favored (highest ranked) training program [nrmp.org]. Positions that were

59 not allocated to any applicant through the use of this matching algorithm are

60 labeled unmatched (unfilled, vacant). We calculated the number of

61 unmatched positions by jurisdiction (states and the District of Columbia) after

62 the completion of the 2013 Specialty Match (4 December 2013) and

63 deducted that number from the total number of fellowship positions

64 nationwide. This SotFM model is commonly referred to as "attrition" or

65 "natural selection".

66

67

68

69

70

71

72

73

74

75

76

77

78

79

80

81

82

83

84

85

86

87

88

89

90

91

92

93

94

95

96

\section{Equal Proportions Model (EPM)}

In this model the total number of fellowship positions per jurisdiction is mathematically calculated from the number of prevalent ESRD patients for each state respectively. Historically, a variant of the current version of the EPM has been used to apportion the total number of a state's legislators to the United States House of Representatives since 1789 (i.e. Hamilton-Vinton, Adams, Dean, Webster, Jefferson and Hill methods) [Schmeckebier, 1952; Crocker, 2010; Congressional Apportionment]. The EPM calculates the total number of legislators for each state from that state's total population. The model was codified in 1929 (2 U.S.C. 2a) and the United States Congress has used the current formula since 1941 [The Permanent Apportionment Act of 1929]. Briefly, the EPM formula begins by apportioning one position to each jurisdiction [Congressional Apportionment]. Subsequent positions are apportioned based on a calculated priority score. The score is derived by using the prevalence of ESRD patients in each jurisdiction and the geometric mean between a given jurisdiction's current number of fellowship positions $(n)$ and its next apportioned position $(n+1)$. This iteration continues until the total number of fellowship positions nationwide has been apportioned.

In this investigation two important rules of apportionment were implemented. First, any jurisdiction whose total number of fellowship positions was zero in the 2013 NRMP Specialty Match (quota) was excluded from the model. Fellowship positions were not apportioned to any of these jurisdictions. Second, no jurisdiction could be apportioned a total number of fellowship positions greater than its 2013 NRMP quota.

Identifying the least burdensome model

Both models were compared head-to-head in two areas. First, the number of jurisdictions that would experience a decrease in their total number of fellowship positions (based on the 2013 NRMP quota for each jurisdiction) was determined. Second, the greatest percent reduction that a jurisdiction would experience was calculated. The model that resulted in 1) the least number of jurisdictions losing fellow positions and 2) the lowest 
97 percent reduction for any single jurisdiction was deemed "least burdensome".

98 The models were considered equally burdensome if they each shared one of

99 these two features.

100 Statistical Considerations

101 Microsoft Excel 2011 (Microsoft, Redmond, Washington) was used to 102 calculate priority scores (see EPM above). JMP Pro 10.0 (SAS, Cary, North 103 Carolina) was used to calculate median, interquartile ranges and generate 104 figures and tables.

105 Results

106 In 2013 there were 8 jurisdictions that had zero positions in the NRMP 107 Specialty Match: Alaska, Hawaii, Idaho, Montana, Nevada, North and South 108 Dakota, and Wyoming. These jurisdictions were excluded from this 109 investigation. The remaining 43 jurisdictions (42 states and the District of 110 Columbia) offered a total of 416 positions (Figure 1 ). There were a total of 111421 applicants for an applicant:position ratio (AP ratio) of 1.01. Forty-seven 112 positions were unmatched and resulted in an $89 \%$ match rate.

113 In the SotFM, these 47 unmatched positions were eliminated from 23 114 jurisdictions (53\% of the total jurisdictions participating in the NRMP Specialty 115 Match). Figure 2 shows the distribution of jurisdictions losing $n$ percent of 116 their quota. The median percent reduction was $-20.00 \%$ (IQR $-12.50 \%$,$11737.50 \%)$. In the EPM a total of 369 positions were apportioned to 43 118 jurisdictions. Each jurisdiction was apportioned 1 position at the start and 119 none were apportioned a total number of positions greater than their 2013 120 NRMP quota. Supplemental Table 1 shows the priority scores for each 121 jurisdiction during each of the 368 rounds of apportionment. Nine 122 jurisdictions were apportioned less fellow positions than their NRMP quota 123 (21\% of the total jurisdictions participating in the NRMP Specialty Match).

124 Figure 3 shows the distribution of jurisdictions losing $\mathrm{n}$ percent of their quota.

125 The median percent reduction was $-33.33 \%$ (IQR $-24.09 \%,-50.00 \%$ ).

126 In the SotFM, Washington suffered the greatest reduction in positions (-

$12766.67 \%$ ) followed by Utah and Alabama (-50.00\% each). In the EPM,

128 Alabama, Vermont, and Virginia suffered the greatest reductions $(-50.00 \%$

129 each).

130 Discussion

131 Decreasing the number of Nephrology fellowship positions will be a 132 challenging, arduous, and difficult process regardless of the method

133 implemented to carry out that reduction. The field of Nephrology (as a 
134 whole) must identify a model that minimizes the systemic burden that will

135 occur when reduction takes place. In this investigation, the EPM reduces the

136 systemic burden in four ways. First, it limits the reductions to only 9

137 jurisdictions (less than a quarter of all jurisdictions) versus 23 jurisdictions

138 (over half of all jurisdictions) seen in the SotFM. Second, the greatest single

139 reduction in the EPM is only $50 \%$, while it is $67 \%$ in the SotFM. Third, the

140 method by which the EPM was implemented in this investigation ensured that

141 no jurisdiction would benefit at the expense of another. Jurisdictions that did

142 not offer fellowship positions in 2013 were not "awarded" fellowship positions

143 in the EPM. Moreover, those jurisdictions that offered positions in the 2013

144 NRMP Specialty Match could not increase their total number of positions at

145 the expense of another jurisdiction. Finally, the EPM reduction model

146 eliminates positions based on patient needs (i.e. the prevalence of ESRD

147 patients) and not on the perception of a fellowship program's prestige and

148 value.

An additional downfall of the SotFM is that it eliminates fellowship positions based on the assumption that applicants avoid positions from less prestigious programs. While the SotFM doesn't require the use of a mathematical formula and does not account for patient needs, its execution is arbitrary and should not be supported. Applicants may not choose certain fellowship positions because of reasons that don't reflect the quality of the fellowship program; such as climate patterns, geopolitical concerns, employment opportunities for spouses, or proximity to family. The SotFM cannot disconnect the personal preferences of an applicant from the educational value or prestige of the program that offers the position.

Lastly, reducing fellowship positions will not directly increase interest in the field of Nephrology. At a minimum reducing the number of positions offered nationwide will make it easier for fellowship programs to match applicants. Historically, fellowship programs with applicant:position ratios (AP) greater than 1.0 have had greater success in filling all positions [Subspecialty Match Report, 2014]. Successful 2-year fellowship training programs such as Rheumatology or Endocrinology have AP ratios of 1.25 and 1.44 , respectively, while another struggling 2-year training program, Infectious Disease, has an AP ratio of 0.89 [National Resident Matching Program, 2013 ]. Eliminating 47 Nephrology fellowship positions would bring the AP ratio from 1.01 to 1.14 (Table 1). A more successful match can have

171 positive consequences; it would allow training programs to devote resources away from the post-match "scramble" and towards more educationally

\section{Additional Considerations}


At the time of this writing, there was no central authority that could mandate a decrease in nephrology positions. Therefore, this investigation 176 serves only as a guide for training programs across the United States. It 177 allows programs to collectively manage the number of available positions 178 and limit the overall burden experienced by a reduction. However, recent recommendations by the Institute of Medicine suggest that a centralized agency, referred to as the "Graduate Medical Education (GME) Center", could develop and enforce a funding plan that controls the number of physicians required to meet the nation's healthcare needs [Wilensky, Berwick, 2014]. The results derived from the EPM would allow such an agency to resourcefully use GME funding to achieve this goal.

It is unclear if other models of reduction exist that can be compared to the 2 models illustrated in this investigation. Alternative models were not found in the literature search preceding the start of this investigation. Arguably a third model would mathematically link the number of fellowship positions (by jurisdiction) to the number of all patients with kidney disease, not just those receiving dialysis. However, there is no centralized database that monitors the total number of patients cared for by kidney doctors. Such a model would rely on internal institutional reports; reports that could be incomplete, inaccurate, and/or not easily validated.

Neither the SotFM nor EPM accounts for positions that are available "outside" of the NRMP Specialty Match program. There is no central agency that tallies these "non-match" positions; if there are many non-match positions then both models could underestimate the burden that each jurisdiction would experience.

\footnotetext{
212 choice for applicants. One would erroneously assume that a model, which
} 
213 reduces positions at "prestigious programs", would be a disservice to the

214 applicant. The EPM, however, does not discriminate between programs

215 considered to be "more prestigious" from those considered to be less. The

216 goal of the EPM is to reduce positions in an objective manner by linking the

217 workforce needs (i.e., fellowship positions) with patient needs (i.e., ESRD

218 prevalence). This method does not factor "prestige" into the mechanism of

219 reduction. Indeed, prestige is subjective; who can decide which program is

220 more or less prestigious when all programs must deliver healthcare to ESRD

221 patients as prescribed by national guidelines? Prestige is transient;

222 prestigious programs today may become less prestigious tomorrow and vice

223 versa. Applicant demand for positions in a particular program doesn't

224 necessarily reflect the prestige of said program. Applicants consider other

225 factors besides program prestige when submitting applications; those factors

226 include but are not limited to 1 ) political issues (e.g., states that are

227 for/against same-sex marriage), 2) weather, 3) proximity to family/friends,

228 and 4) employment opportunities for spouses. The fact that the EPM is blind

229 to all subjective factors, such as prestige, state politics, weather, etc.,

230 supports the conclusion that it is an equitable model.

231 The EPM model described in this investigation is operationalized at the

232 state level. The calculations are not granular enough to dictate how or which

233 specific training programs should reduce their number of positions. As in the

234 apportionment of representatives to the US House, decisions regarding the

235 distribution of positions across programs of a specific jurisdiction should

236 remain a "local" one. The EPM model allows program directors within a

237 jurisdiction to reach a consensus in how and where positions should be

238 reduced. For example, program directors can collaborate to reduce positions

239 equitably and/or preferentially from particular tracks (research over clinical).

240 In the EPM, jurisdictions are afforded the flexibility they need to successfully

241 reduce the number of training positions.

\section{Conclusion}

243 In this investigation two models were compared to determine which

244 provided the least burden to the nation when reducing the number of

245 Nephrology fellowship positions. The Equal Proportions Method (EPM),

246 historically used to apportion legislators to the US House since 1789,

247 mathematically links the needs of the ESRD population to the number of

248 fellowship positions offered. The EPM is blind to the prestige of a fellowship

249 training program or to the personal (non-professional) preferences of an 
250 applicant. This model should be considered and implemented if the field of

251 Nephrology wishes to improve its matching rate.

252 Figure 1

253 Fraction of unmatched spots in the 2013 NRMP Specialty Match for

254 Nephrology

255 Figure 2

256 Jurisdictions experiencing a reduction in fellowship positions (percent) in the 257 Survival of the Fittest Model

258 Figure 3

259 Jurisdictions experiencing a reduction in fellowship positions (percent) in the 260 Equal Proportions Model

261 Supplemental Table 1

262 Priority scores for each jurisdiction. Yellow highlighted cell indicates the 263 jurisdiction with the highest priority score for that round.

264 Table 1

2652013 NRMP Specialty Match Data for 2-year fellowship training programs

266 Legend: *denotes applicant:position ratio 
1. Jhaveri KD, Sparks MA, Shah HH, Khan S, Chawla A, Desai T, Iglesia E, Ferris M, Parker MG, Kohan DE. 2013. Why Not Nephrology? A Survey of US Internal Medicine Subspecialty Fellows. American Journal of Kidney Diseases. 61(4): 540-546.

2. Desai T, Ferris M, Christiano C, Fang X. 2012. Predicting the Number of US Medical Graduates Entering Adult Nephrology Fellowships Using Search Term Analysis. American Journal of Kidney Diseases. 59: 467469.

3. Desai T. 2014. Alternative ideas to increase the percentage of filled seats in nephrology fellowships. F1000Research. 3(3):1-5.

4. Berns JS, Ellison DH, Linas SL, Rosner MH. 2014. Training the Next Generation's Nephrology Workforce. Clinical Journal of the American Society of Nephrology. 9(9): 1639-1644.

5. Salsberg E, Masselink L, Wu X. 2014. The US Nephrology Workforce: Developments and Trends. Washington, DC: American Society of Nephrology.

6. National Resident Matching Program, Results and Data: Specialties Matching Service 2013 Appointment Year. 2013. National Resident Matching Program, Washington, DC.

7. U.S. Renal Data System, USRDS 2013 Annual Data Report: Atlas of Chronic Kidney Disease and End-Stage Renal Disease in the United States. 2013. National Institutes of Health, National Institute of Diabetes and Digestive and Kidney Diseases, Bethesda, MD.

8. Crocker R. 2010. The House of Representatives Apportionment Formula: An Analysis of Proposals for Change and Their Impact on States. Congressional Research Service. Available at https://www.fas.org/sgp/crs/misc/R41382.pdf (accessed on 1 February 2014)

9. Schmeckebier LF. 1952. The Method of Equal Proportions. Law contemp. Problems. 17: 302-313.

10. Congressional Apportionment. Available at http://www.census.gov/population/apportionment/about/computing.htm I (accessed on 1 February 2014). 
301 11. The Permanent Apportionment Act of 1929. The United States House of Representatives. Available at http://history.house.gov/Historical-Highlights/1901-1950/ThePermanent-Apportionment-Act-of-1929/ (accessed on 1 February 2014). 12. Subspecialty Match Report 2014. Alliance for Academic Internal Medicine. Available at http://www.im.org/AcademicAffairs/match/Pages/MovetheMatch.aspx (accessed on 1 February 2014)

13. Wilensky GR, Berwick DM. 2014. Reforming the Financing and Governance of GME. The New England Journal of Medicine. DOI 10.1056/NEJMp1406174.

14. 2013 MMS Physician Workforce Study. Massachusetts Medical Society. Available at http://www.massmed.org/workforce2013.

(accessed on 1 February 2014).

15. Rumack CM. 2013. Graduate Medical Education 2012-13 Annual Report. Available at

http://www.ucdenver.edu/academics/colleges/medicalschool/education/ graduatemedicaleducation/GMEDocuments/Documents/Annual \%20Report.pdf (accessed on 1 February 2014).

16. Tucker C, Jeffrey C, Calp C, Dever GEA. 2012. Physician Supply and Demand Indicators in Georgia: A Survey of Georgia's GME Graduates Completing Training in June 2012. Available at http://www.gbpw.georgia.gov (accessed on 1 February 2014). 17. Seifer SD, Vranizan K, Grumbach K. 1995. Graduate Medical Education and Physician Practice Location: Implications for Physician Workforce Policy. Journal of the American Medical Association. 274(9): 685-691.

18. Packham J, Gonzales C, Griswold T. 2012. University of Nevada School of Medicine's Exiting Medical Residents Annual Survey 2011. UNSOM Health Policy Brief. Available at http://www.medicine.nevada.edu/ohprp/documents/UNSOM_HP_Brief_RES_2011_-Jan_2012.pdf (accessed on 1 February 2014). 19. Owen JA, Hayden GF, Bowman RC. 2005. Influence of Places of Birth, Medical Education, and Residency Training on the Eventual 
335 Practice Locations of Family Physicians: Recent Experience in Virginia. Southern Medical Journal. 98(6): 674-675. 


\section{Table $\mathbf{1}$ (on next page)}

2013 NRMP Specialty Match Data for 2-year fellowship training programs

*denotes applicant:position ratio 


\begin{tabular}{|c|c|c|c|c|}
\hline Fellowship & $\begin{array}{c}\text { Applican } \\
\text { ts }\end{array}$ & $\begin{array}{c}\text { Positio } \\
\text { ns }\end{array}$ & AP* Ratio & $\begin{array}{c}\text { Matched Positions } \\
(\%)\end{array}$ \\
\hline Nephrology & 421 & 416 & 1.01 & 89 \\
\hline Endocrinology & 361 & 251 & 1.44 & 95 \\
\hline Rheumatology & 244 & 195 & 1.25 & 95 \\
\hline $\begin{array}{c}\text { Infectious } \\
\text { Disease }\end{array}$ & 288 & 334 & 0.86 & 81 \\
\hline Pulmonary & 96 & 22 & 4.4 & 100 \\
\hline Oncology & 120 & 31 & 3.9 & 94 \\
\hline Hematology & 99 & 15 & 6.6 & 100 \\
\hline
\end{tabular}




\section{1}

Fraction of unmatched spots in the 2013 NRMP Specialty Match for Nephrology

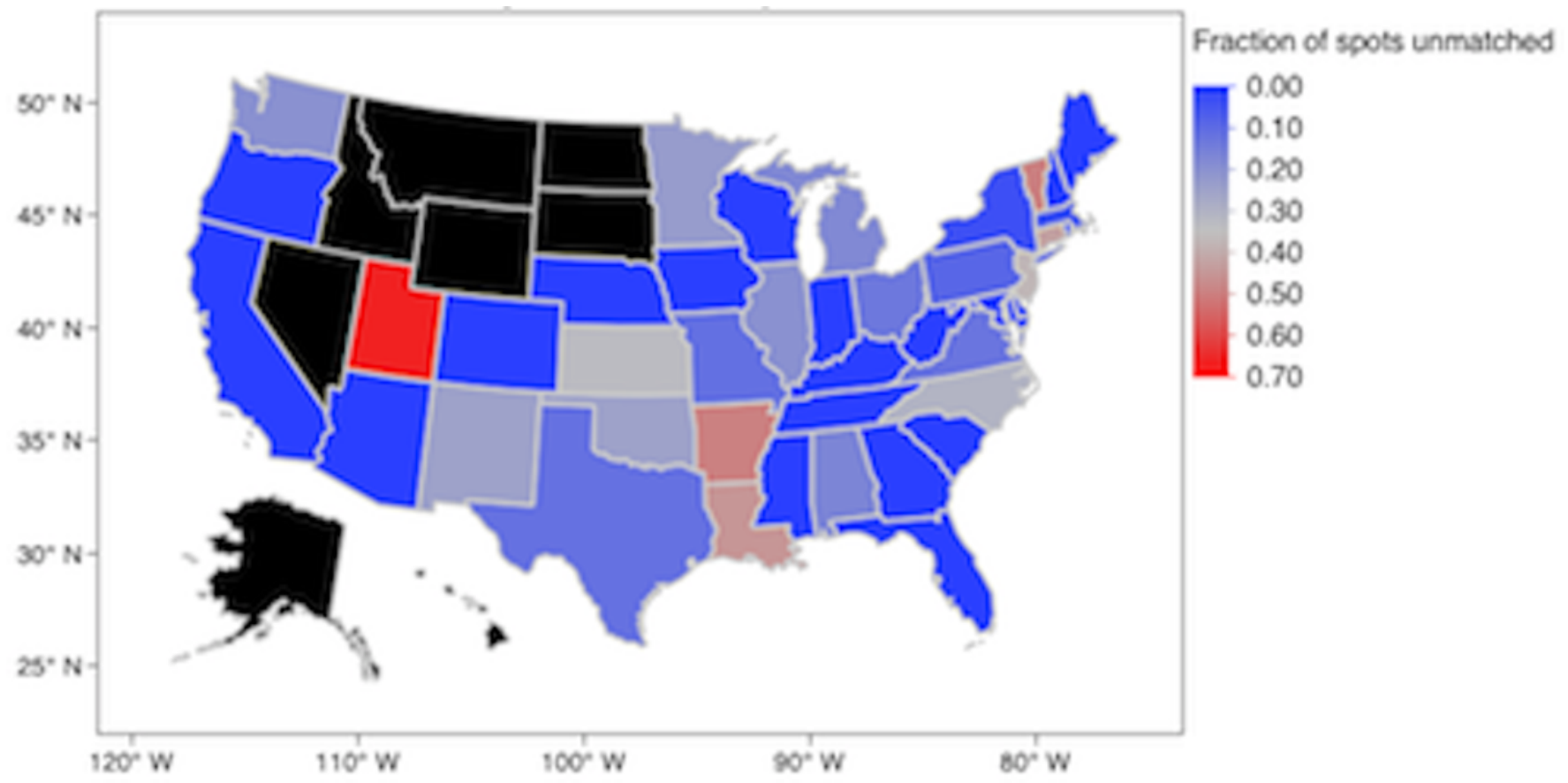


2

Jurisdictions experiencing a reduction in fellowship positions (percent) in the Survival of the Fittest Model

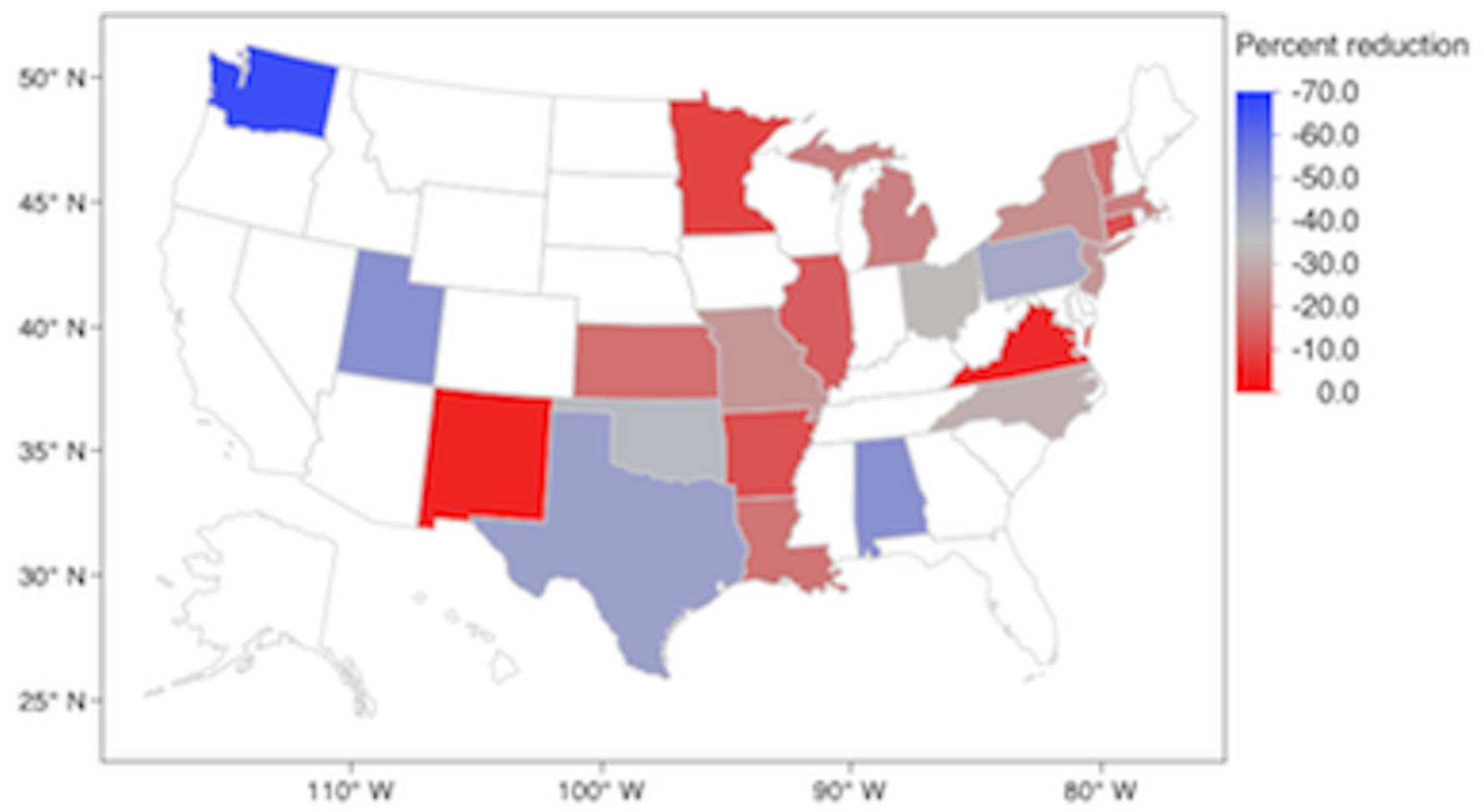


3

Jurisdictions experiencing a reduction in fellowship positions (percent) in the Equal Proportions Model

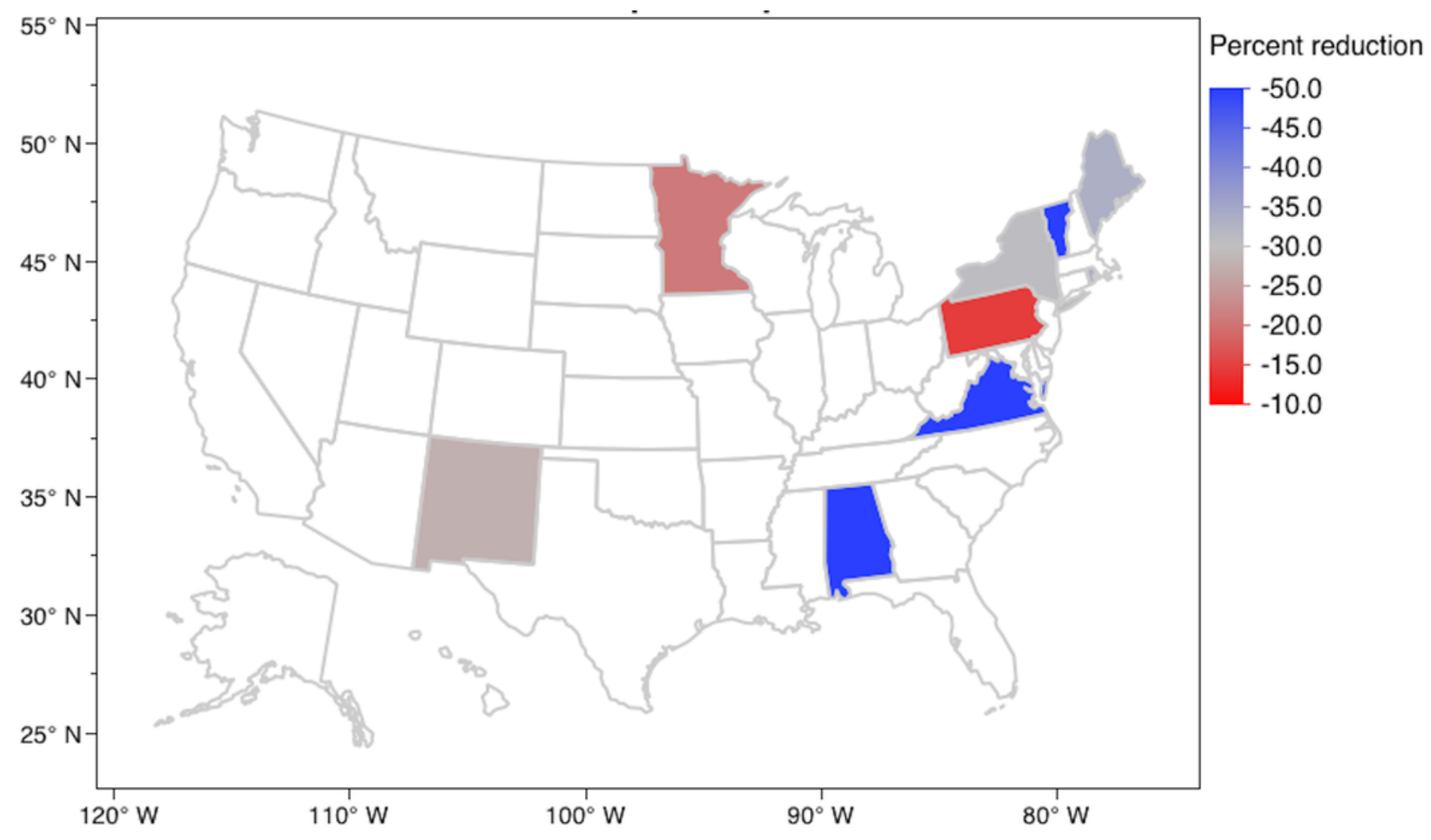

